- Revista de Iniciação à Docência, v. 2, n. 2, 2017 -

Publicação: março, 2018 - ISSN 2525-4332

\title{
INFLUÊNCIA DO PIBID-UESB NA CONSTRUÇÃO DA IDENTIDADE DOCENTE DE LICENCIANDOS DE CIÊNCIAS BIOLÓGICAS
}

\author{
Liz Batista Mendonça ${ }^{1}$ \\ Moisés Nascimento Soares ${ }^{2}$
}

RESUMO: O artigo é um recorte de um trabalho de conclusão de curso que se propôs investigar se alunos do curso de Licenciatura em Ciências Biológicas da UESB-Jequié, participantes do Programa Institucional de Bolsas de Iniciação à Docência - PIBID, atribuíram alguma influência do referido programa no despertar ou não do desejo de almejar a carreira docente. A pesquisa realizada teve cunho qualitativo e os sujeitos participantes foram 8 alunos, cursistas do último semestre da referida Licenciatura. $O$ instrumento utilizado para coleta de dados foi a entrevista semi-estruturada e a análise dos dados foi feita através de análise de conteúdo. Os resultados mais relevantes citados nas respostas dos entrevistados, para cada categoria foram: a importância da relação teoria e prática nas atividades desenvolvidas no Programa; o processo de mudanças por eles sofrido, percebido como fundamental para a construção de suas identidades; e as especificidades de cada subprojeto, que ajudaram a promover experiências inteiramente particulares, sendo importantes para a compreensão de quais influências foram relevantes para despertar o interesse em ingressar na carreira docente.

Palavras-Chave: Identidade Docente; Licenciatura; Ciências Biológicas; PIBID.

\section{Introdução}

Este artigo é um recorte de um trabalho de conclusão de curso (TCC) intitulado "As influências do PIBID na formação identitária de alunos do curso de Ciências Biológicas da UESB" onde se buscou analisar de que forma o Programa pode ou não imprimir suas marcas no processo de formação da identidade docente destes alunos.

O Programa Institucional de Bolsas de Iniciação à Docência - PIBID tem se apresentado como um parceiro da melhoria da formação inicial de professores. Várias pesquisas têm buscado analisar as contribuições deste Programa para a formação inicial de licenciandos.

\footnotetext{
1 Mestranda do Programa de Pós-Graduação em Educação Científica e Formação de Professores, Universidade Estadual do Sudoeste da Bahia, Jequié-BA. E-mail: lizbmendonca@gmail.com

2 Docente do Departamento de Ciências Biológicas (DCB/UESB) e do Programa de Pós-Graduação em Educação Científica e Formação de Professores, Universidade Estadual do Sudoeste da Bahia, Jequié-BA. E-mail: moiseshs@yahoo.com.br
} 
Gonçalves e Morais (2014), por exemplo, buscaram refletir sobre as contribuições do PIBID para formação inicial de professores e concluíram que as experiências vivenciadas pelos alunos participantes do programa foram capazes de diminuir a distância entre os graduandos e a realidade escolar. Já Wiebusch e Ramos (2012) investigaram as repercussões do PIBID na formação inicial e puderam concluir que a participação em tal programa tem grande contribuição tanto no âmbito pessoal, quanto no profissional, pois possibilita a construção e produção de saberes que os auxiliarão em suas práticas docentes futuras.

Por sua vez, Gama et al. (2014) analisaram a importância do PIBID para a formação de alunos de licenciatura em Química de uma universidade. Os autores indicam que o programa proporcionou aos alunos um conhecimento prévio em sua atuação como futuros professores e estes atribuíram grande contribuição do programa para sua formação. Por fim, Siqueira et al. (2013) desenvolveram pesquisa que investigou como o PIBID contribui para a construção da identidade e dos saberes docentes de alunos do curso de licenciatura em Ciências. Os autores encontraram evidências de que ele alcança sucesso na aproximação da universidade com a educação básica e proporciona aos alunos experiências capazes de contribuir e enriquecer a formação inicial dos licenciandos.

Ao analisarmos outras pesquisas que olharam para as possibilidades trazidas pelo PIBID, podemos perceber que, na grande maioria dos casos, ele deixa fortes impressões na formação dos alunos de licenciatura. Vale ressaltar que, apesar de se mostrar como importante mediador para tentar minimizar a distância entre universidade e educação básica, e dessa forma proporcionar aos alunos dos cursos de licenciatura uma formação mais eficiente, o PIBID, assim como qualquer outra política pública de incentivo à docência, se executada de maneira isolada, não pode ser capaz de solucionar os entraves encontrados nos cursos de formação de professores, como por exemplo, certa superficialidade do contato com a prática escolar durante o curso. Diante disso, analisamos quais marcas o PIBID deixou nos alunos da Licenciatura em Ciências Biológicas da UESB, buscando compreender como o Programa participou do processo de construção identitária desses alunos.

\section{Fundamentação Teórica}

Ao pensarmos sobre o fato de identificarmo-nos com alguma coisa, é coerente entendermos que esse acontecimento nem sempre se dá num passe de mágica, isto é, do dia para a noite. A princípio, nossas afinidades, aproximações e gostos vão sendo sedimentados durante um tempo significativo, por meio do contexto histórico e social no qual realizamos nossas vivências.

Para Ciampa (2012) a identidade pode ser entendida na relação entre diferença e igualdade, continuamente estabelecida dentro dos grupos sociais nos quais estamos 
- Revista de Iniciação à Docência, v. 2, n. 2, 2017 Publicação: março, 2018 - ISSN 2525-4332

inseridos. Nesse sentido ele ainda define que: "é do contexto histórico e social em que o homem vive que decorrem suas determinações e, consequentemente, emergem as possibilidades ou impossibilidades, os modos e as alternativas de identidade" (CIAMPA, 2012, p. 72).

Ao definirmos nossas escolhas, tanto pessoais quanto profissionais também somos fortemente influenciados pela nossa identidade. No entanto a construção da identidade é mutável e encontra-se em constante transformação, que conforme o mesmo autor pode ser definida como "(...) o processo permanente de formação e transformação do sujeito humano, que se dá dentro de condições materiais e históricas dadas" (CIAMPA ,1998, p. 88).

Dessa forma fica evidente como o contexto em que estamos inseridos vai participar diretamente da construção das identidades profissionais. No que se refere à identidade docente podemos pensar nos alunos que ingressam nas licenciaturas de forma aleatória, obviamente sem uma identidade profissional formada. Esses discentes ao adentrarem no ambiente universitário certamente começam a fazer parte de uma realidade com grande potencial de os ajudarem a desenvolverem a construção de sua identidade docente.

Um fator de grande relevância na construção da identidade docente é a trajetória do aluno no curso de licenciatura. É muito importante que haja, desde o início da graduação, a inserção dos alunos no ambiente escolar. Dessa forma teoria e prática devem estar associadas constantemente para contribuir com a aproximação dos alunos com a sua futura profissão.

No entanto, segundo Pereira (2011), há muito se vê a falta de articulação entre as disciplinas de conteúdo específico e as de cunho pedagógico. Outra realidade presente nos cursos de licenciatura é a de que os alunos destes cursos não se identificam como professores de ciências e sim como biólogos, dando prioridade na maioria das vezes em participar de projetos de iniciação científica, se distanciando dos trabalhos e pesquisas no âmbito da educação.

Como forma de apresentar ao alunado o ambiente escolar e com a oportunidade de articular a teoria dos conteúdos programáticos dos cursos de licenciatura com a prática docente tem-se o estágio supervisionado ofertado pelas grades curriculares das licenciaturas. Os estágios configuram-se como "uma oportunidade de inserção numa realidade [...] permitindo a confrontação do saber acadêmico com o saber da escola, permitindo aos estudantes apreender como se dão as relações de trabalho" (SANTOS; STHAL, 2012, p. 208). Para o referido autor, o estágio ainda tem o potencial de preparar os licenciandos para uma possível contribuição na formação de professores.

Um entrave identificado na realização dos estágios é o fato das atividades acontecerem nos semestres finais, tal como ressaltado por Santos e Sthal (2012). Para os autores o contato 
- Revista de Iniciação à Docência, v. 2, n. 2, 2017 Publicação: março, 2018 - ISSN 2525-4332

de forma antecipada proporcionaria aos alunos a ratificação da sua escolha profissional e evitaria também a frustração com a profissão "tardia" que muito deles sentem quando se deparam com o estágio.

Mesmo diante disso não podemos deixar de considerar a importância do estágio na formação inicial dos discentes, bem como, a possibilidade por ele oferecida em ajudar os alunos a solidificar a construção da sua identidade docente.

Outra realidade que está inserida no contexto das licenciaturas de diversas universidades brasileiras é o Programa Institucional de Bolsas de Iniciação à Docência - PIBID, que surgiu com o importante objetivo de estreitar a distância da universidade com a educação básica, além de trazer propostas de melhoria à qualidade da formação inicial de professores e promover a articulação entre teoria e prática como forma de elevar a qualidade das atividades acadêmicas dentro dos cursos de licenciatura (CAPES, 2008).

Diante dos trabalhos citados no início do artigo fica evidente que os resultados obtidos por pesquisas debruçadas em mostrar avanços por meio do PIBID, confirmam a tentativa deste em levar os licenciandos para mais perto da prática escolar. O programa caminha na perspectiva de aproximação entre teoria e prática, com o intuito de integrar os alunos às realidades de sua profissão e assim gerar uma maior identificação deles com a prática escolar.

Nesse sentido Albino e Maganha (2014) ressaltam a importância de "mobilizar os saberes da experiência, os saberes pedagógicos e os saberes científicos, como constitutivos da docência nos processos de construção da identidade de professores" (p.3). É certo que se não existe concretização da teoria na prática, não há a aproximação necessária para que haja uma identificação com a profissão. $O$ processo de construção da identidade docente acontece através das vivências da realidade e do contexto social (CIAMPA, 2012).

Diante disso, gostaríamos de ressaltar que os objetivos do PIBID apresentam potencial para contribuir na formação inicial de alunos dos cursos de licenciatura, principalmente porque estes estão focados em levar ao aluno o contato inicial com a escola muito antes do estágio supervisionado oferecido nas licenciaturas.

Com isso, acreditamos que se o PIBID tem como prioridade a inserção dos licenciandos na realidade escolar como forma de promover o exercício de uma proposta pedagógica pautada na relação teórico-prática, devemos elucidar a importância dessa concretização no processo da construção da identidade dos alunos com a docência. Como já discutimos, as vivências dos alunos estão intimamente articuladas à sua identificação profissional. Sendo assim, o PIBID, ao proporcionar tais oportunidades, estará contribuindo grandemente para que, a partir do maior envolvimento dos alunos com a escola, eles sejam levados à uma maior identificação com sua futura profissão. 


\section{Procedimentos Metodológicos}

A abordagem desta pesquisa é qualitativa, pois segundo Minayo (2002), tem capacidade de responder a questões muito particulares, e sua preocupação é com a realidade que não pode ser quantificada. Seu caráter exploratório permite que os entrevistados participem da investigação de maneira mais livre. Ainda de acordo com a autora esse tipo de investigação "requer como atitudes fundamentais a abertura, a flexibilidade, capacidade de observação e de interação com o grupo de investigadores e com os atores sociais envolvidos" (MINAYO, 2002, p. 101).

O cenário no qual se desenvolveu a pesquisa foi a Universidade Estadual do Sudoeste da Bahia-UESB, campus de Jequié/BA. Os participantes da pesquisa foram oito estudantes do curso de Licenciatura de Ciências Biológicas que na época da realização do trabalho (ano 2014) cursavam o $8^{\circ}$ semestre do curso. Todos estes alunos foram participantes do PIBID.

As licenciaturas do campus de Jequié, desde 2010, integraram-se ao PIBID-UESB, que na referida instituição foi intitulado "PIBID-UESB Micro Rede Ensino-Aprendizagem-Formação: Ressignificando a Formação Inicial e Continuada de Professores”, com a participação das licenciaturas dos cursos de Biologia, Pedagogia, Letras, Matemática, Química, Educação Física, Teatro e Dança (UESB, 2014).

Os subprojetos alcançados pela pesquisa foram aqueles nos quais os alunos entrevistados participaram durante sua trajetória no PIBID, são eles: Biologia e Interdisciplinar, nas linhas de ações de Educação de Jovens e Adultos, Educação Ambiental e Educação Especial.

Como instrumento de coleta de dados foi utilizado a entrevista semi-estruturada (GIL, 2002). Através da análise das respostas obtidas por meio das entrevistas elaboramos categorias. As perguntas do roteiro de entrevistas foram organizadas em eixos-temáticos, de forma que nos permitiu direcionar a condução da entrevista para os objetivos da pesquisa. A partir das análises foram buscados núcleos de sentido comuns nas falas dos participantes, configurando diferentes temas, de modo que estes foram aglutinados em diferentes categorias (BARDIN, 1977). Foram construídas seis categorias. São elas: 1) Despertando para a identidade docente a partir da experiência com o PIBID; 2) O PIBID como possível aliado na superação da crise docente; 3) Sondando os motivos que levaram os discentes a interessar-se pelo projeto; 4) Como se deu o processo de mudanças dos discentes no decorrer da execução do programa; 5) Entendendo de que maneira se entrelaçaram teoria e prática durante a trajetória do programa; 6) A especificidade dos subprojetos imprimindo marcas nas itinerâncias dos discentes que passaram pelo PIBID. 
- Revista de Iniciação à Docência, v. 2, n. 2, 2017 Publicação: março, 2018 - ISSN 2525-4332

Neste artigo serão apresentados apenas os resultados relativos às categorias 4, 5 e 6, tendo em vista que as anteriores foram exploradas em outro artigo já publicado (MENDONÇA; SOARES, 2015).

\section{Resultados e Discussões}

$\mathrm{Na}$ categoria intitulada "o processo de mudanças dos discentes no decorrer da execução do programa" foram analisados três temas, o primeiro denominado "amadurecendo através das descobertas no cenário escolar". Abaixo exemplo da fala de um entrevistado sobre essa temática:

"foram muitas metamorfoses (risadas), foram muitas, tivemos momentos de amores e de desamores, vamos pôr assim, a gente teve um relacionamento de casamento (risadas), tem a crise, teve o divórcio,

a crise que antecede o divórcio, depois vem a paixão; foi a mesma coisa, tivemos dificuldades nas escolas e aí essas dificuldades deram um banho de água fria na gente no primeiro momento, tanto em mim quanto nas meninas, nas minhas colegas, e aí esse primeiro momento foi aquele momento de poxa é isso que eu quero, aí tá complicado, aí teve o momento de paixão que a gente conheceu outro universo, poxa muito interessante, em outra escola já, então foram momentos realmente metamorfósicos, eu realmente amadureci, eu vi que não vai ser uma perfeição, que não vai ser uma estável, vai haver mudanças a todo momento, mas realmente eu passei pelo processo de decepção, passei pelo processo de alegria, processo de adaptação porque você se adapta as escolas querendo ou não e hoje eu passo por um momento assim de realização, eu me sinto realizada" (E01).

O segundo tema examinado foi intitulado "passou a enxergar algo de bom em ser professor, o que antes de ingressar no projeto não conseguia ver". Abaixo trechos de falas de entrevistados que caminham nesse sentido:

"Inicialmente quando eu entrei na graduação eu não era muito adepta da educação, e assim o PIBID me fez olhar, ter um outro olhar sobre a educação, de forma que hoje em dia eu, eu consigo né ver a educação de uma forma, mais prazerosa, antes eu tinha uma visão de que ser professor era um martírio, era só aquela coisa maçante, aquela coisa chata e depois de participar do PIBID eu pude

perceber que não é só isso, tem algo de bom em ser professor também, entendeu?" (E02).

"[...] eu não tinha assim, não era muito atraída pela educação, achava que a educação era coisa chata, ser professor era uma coisa chata; não queria ser professor de jeito nenhum, e hoje em dia eu já eh consigo me ver como uma professora entendeu? Então acho que o processo né de ter participado do PIBID me abriu novos horizontes nesse campo, nessa área da educação, então hoje já eu consigo me considerar como uma professora e eu já penso sim em seguir a carreira, não vou dizer pra você que eu vou ficar só na sala de aula" (E02).

Nessa categoria procuramos analisar quais mudanças ocorreram com os alunos durante o processo de atuação no PIBID. O que se objetivou foi identificar nas falas dos discentes a percepção deles quanto a possibilidade de projetos como este proporcionarem mudanças em si mesmos, no decorrer de sua participação. As falas nos revelam que os alunos atribuíram ao PIBID algumas mudanças ocorridas após ingressarem no projeto. Para E02 o 
PIBID deu condições para que ele tivesse um outro olhar sobre a educação. E02 percebeu que suas opiniões a respeito da educação e do ensino foram alteradas durante a realização das atividades desenvolvidas, "de forma que hoje em dia eu, eu consigo ver a educação de uma forma mais prazerosa".

Tanto E01 como E02 perceberam-se mudando suas concepções sobre a forma como viam a educação antes desse contato direto em sala de aula através das atividades realizadas pelo PIBID.

As falas sobre mudanças também podem ser indicadas quando E01 diz que "foram momentos realmente metamorfósicos, eu realmente amadureci" (grifo nosso). Este mesmo entrevistado diz que os momentos de decepção na escola, que a princípio "deram um banho de água fria na gente, no primeiro momento foi como o momento de crise de um relacionamento, mas que depois com as experiências positivas de outros momentos, veio o momento da paixão, onde conhecemos outro universo". Percebemos assim, que as decepções, alegrias e adaptações foram momentos fundamentais para que o aluno se sentisse, enfim, melhor realizado.

Outros trabalhos que buscaram entender o PIBID na perspectiva da construção identitária, como o de Felício (2014, p. 11), mostram que "o reconhecimento do PIBID como vivência tem contribuído para o processo de construção da identidade do professor". Para ele isso é possível porque as experiências acontecem no ambiente escolar que é o futuro campo de atuação do licenciando.

Ainda segundo o autor, o PIBID é considerado como um espaço de concretização efetiva da relação entre teoria e prática. Felício (2014) acredita que este se diferencia do estágio curricular obrigatório, pois possibilita uma inserção prévia e continuada dos licenciandos na prática escolar.

Diante do exposto, temos alguns indícios que começam a apontar para as possíveis contribuições, influências e impactos do PIBID sobre a formação inicial de alunos dos cursos de licenciatura.

Outra categoria foi intitulada como "entendendo de que maneira se entrelaçaram teoria e prática durante a participação no PIBID". Nela foram elaborados três temas dos quais o primeiro foi denominado "vivenciando teoria e prática através dos grupos de estudos", como mostra o exemplo abaixo:

\footnotetext{
“...o nosso tempo do Pibid era distribuído em momentos de reunião de estudo, de planejamento das intervenções e outros momentos...dividia praticamente em três momentos que era o momento geral com todos os participantes do subprojeto de Biologia regular e o momento de planejamento que ocorria entre os bolsistas e o supervisor e os momentos de estudo que também era geral, então existia esses momentos de estudo, de preparação pra ocorrer a prática" (E04)
} 
- Revista de Iniciação à Docência, v. 2, n. 2, 2017 Publicação: março, 2018 - ISSN 2525-4332

O segundo tema definido foi "percebendo que não tem como realizar uma boa prática sem embasamento teórico, e o projeto proporcionou essa junção". Eis o exemplo abaixo que explicita um pouco esse tema:

“...porque se a gente pega a prática sem teoria a gente teria sofrido muito mais, sofrido o triplo, porque tem coisas que você, na licenciatura, dentro de uma escola, você não consegue compreender se você realmente não tiver o embasamento teórico, imagine você chegar lá pra lidar com deficiente sem ter embasamento teórico nenhum, certamente não saberia como agir diante desse aluno, ou seja: sem a teoria a prática também não acontece"( E01).

O terceiro tema foi denominado "os momentos de estudo eram realizados de maneira coletiva". Eis abaixo um exemplo que ressalta a importância dos momentos de coletividade como forma de contribuição nas experiências vivenciadas pelos licenciandos:

"Sim, principalmente porque havia principalmente troca de ideias, a aula em si que era planejada não era individualmente, eu pensava em alguma coisa ou outra pessoa pensava em coisas diferentes era planejado em conjunto, no coletivo" (E04).

A maioria dos entrevistados ressaltou que os momentos de estudo aconteciam em coletividade; E05 diz que "foi bem esse processo de grupo de estudos, passar a tarde toda discutindo, fazendo leituras e tal". Eles consideraram esses momentos em conjunto muito úteis para auxiliar as intervenções: "hoje eu vejo que foi fundamental esse processo de ter os momentos de estudo, ter o momento das discussões e, por fim, ter o momento da prática" (E05).

Nessa categoria buscou-se entender como se deu a relação entre teoria e prática, como aconteceram as atividades de maneira que pudessem viabilizar essa relação, e se os alunos conseguiriam perceber a relevância dessa relação para que o trabalho fosse aplicado com coerência. Para Zeichner (2010) é importante que se tenha no decorrer da formação inicial espaços que proporcionem a interação entre teoria e prática, onde ambas sejam importantes e não haja necessidade de uma se sobrepor a outra.

Em linhas gerais, os entrevistados relataram o acontecimento dos momentos de estudos baseados nos teóricos para que pudessem ir preparados na realização das intervenções em sala de aula. Abaixo temos um exemplo:

"Teoria e prática andou junto constantemente, a gente nunca fazia nada antes da gente ler um teórico, buscar uma fundamentação, só depois que a gente partiu pra prática. Foi importante a relação teoria e prática porque sem uma fundamentação teórica a gente ia chegar muito cru, muito sem conteúdo e pra prática é necessário, a gente não pode chegar na prática de mãos vazias, a gente precisa antes estar estudando, buscando pra a gente chegar e poder ter um êxito, porque se a gente não tiver essa teoria, essa fundamentação com certeza nossa prática não vai ter o objetivo alcançado". E07

Diante dos relatos que elucidam os momentos teórico-práticos do PIBID podemos perceber que essa efetividade nos momentos de realização das atividades do projeto foi 
fundamental para aproximar os participantes da sala de aula, de chegarem aos momentos de intervenção realmente preparados para colocarem em prática todo o aprendizado adquirido nos momentos de estudo que aconteciam antes de partirem para a prática nas escolas. Outro fator interessante observado é a forma que os alunos enxergaram os momentos teóricos realizados, assumindo-os como algo que possibilitou grande aprendizado. Eis abaixo exemplo:

"no início foi um desafio né, porque a gente não estava acostumada a passar uma tarde toda lendo artigo, discutindo e surgindo perguntas, tendo que apresentar, discutir vários teóricos, foi muito difícil essa prática, no início foi bem complicado porque ninguém estava acostumado com essa situação. Mas depois a gente começou a perceber que esses momentos dos grupos de estudo; esse momento da discussão, do debate, da reflexão foi importante porque quando a gente chegava na prática a gente começava a elaborar os planos para trabalhar na escola; a gente viu a necessidade que teve desse momento de discussão, esse momento de tirar as dúvidas, foi bem importante porque na prática a gente chegava lá e encontrava um aluno com uma especificidade, aí a gente lembrava: "ah fulano já falou disso lá, a gente pode trabalhar dessa forma e tal"; esse processo foi fundamental , foi primordial para que tudo desse certo durante o tempo da minha participação no Pibid" (E05).

O licenciando E05 assume a dificuldade que enfrentou no início do projeto, pois reconhece que não estava acostumado com esses momentos intensos de leitura. Apesar disso, tanto E05, quanto os outros entrevistados, assumiram a importante contribuição desses momentos teóricos para alcançarem melhorias ao partir para a prática.

Um cenário marcante relatado pelos sujeitos da pesquisa foi o ambiente de estudos. As reuniões eram "momentos dos grupos de estudo, esse momento da discussão, do debate". Eles destacaram que sempre estudavam em coletividade. Eles puderam perceber a "necessidade que teve desse momento de discussão, esse momento de tirar as dúvidas". Para E05 "esse processo foi fundamental... foi primordial para que tudo desse certo durante 0 tempo da minha participação no Pibid".

Contudo faz-se necessário ressaltar que nenhum dos entrevistados demonstrou aversão a esses encontros em que se estudava apenas a teoria. Apesar de E05 declarar que "no início foi um desafio...porque a gente não estava acostumada a passar uma tarde toda lendo artigo"; "discutir vários teóricos", não encontramos registros nas falas dos alunos que revelassem desgosto por parte dos participantes em estar fazendo parte do cenário de estudo teórico.

Sendo assim, podemos inferir que o entrelaçamento da teoria com a prática ocorreu de maneira significativa e participativa, mesmo se considerarmos que os entrevistados participaram de subprojetos diferentes, as análises das falas de cada um deles corroborou com a elaboração de um sentido de destacar a relevância da relação teoria e prática.

Porém, mesmo diante do exposto pelos entrevistados é preciso lançar um olhar cuidadoso sobre o desenvolver dessa prática. Esta precisa ser pensada, articulada e 
- Revista de Iniciação à Docência, v. 2, n. 2, 2017 Publicação: março, 2018 - ISSN 2525-4332

concretizada considerando a reflexão efetiva do futuro professor. Caso contrário corre-se o risco de se realizar uma atividade de caráter técnico, como abaixo nos sugere Carminati:

\begin{abstract}
Muitas vezes, por estarem submetidos a uma dinâmica de trabalho que não os permite refletir ou atribuir significados às suas ações docentes, os professores são conduzidos por um tipo de racionalidade técnica, que infelizmente, para muitos, trabalhar dessa maneira é prova de honestidade moral e seriedade intelectual, mesmo que isto lhes custe a morte da arte de ensinar, do prazer de pensar, sentindo-se com a consciência tranquila e do dever cumprido (CARMINATI, 2006, p. 78).
\end{abstract}

Consoante ao que foi exposto, Fiorentini e Castro (2003) alertam que "embora aconteçam num mesmo tempo, teoria e prática podem apresentar-se apenas justapostas, não se estabelecendo entre elas uma relação efetivamente dialética" (p. 153).

Para Vicente (2014) o modelo curricular reinante nos cursos de formação separa a teoria da prática, o que não condiz com a atuação docente. Para a autora essa separação gera um predomínio da teoria em detrimento da prática, como se esta fosse apenas o ato de aplicar os conhecimentos teóricos. Vicente (2014, p. 5) acredita que "a articulação entre a teoria e a prática deve ser o eixo dos cursos de formação, de modo a habilitar o futuro professor a se tornar autor de sua própria prática, com base em seus conhecimentos teóricos articulados à realidade onde atua".

Nesta última categoria intitulada "a especificidade dos subprojetos - imprimindo marcas na itinerância dos discentes que passaram pelo PIBID”, foram analisados três temas. O primeiro deles foi intitulado como: "identificação com a proposta do subprojeto EJA, contribuindo para uma maior aproximação da educação". Abaixo um exemplo da ideia proposta pelo tema:

"...e o que eu achei assim mais interessante é que eu me identifiquei muito com o público ao qual a gente estava trabalhando, no caso nós trabalhamos com o eixo 6 e 7, aí como eu disse eu não tinha essa afinidade pela área, mas quando eu comecei a trabalhar com os meninos do EJA, , acho que até pela proposta do EJA que é diferente assim, uma proposta diferenciada eu acho que acabou me atraindo" (E02).

O segundo tema elaborado foi o seguinte: "descobrindo através do subprojeto as diferenças nas modalidades de ensino". Eis abaixo exemplo de outro trecho da fala de E01:

“...mas o fato de eu conseguir rever minha posição em relação a educação a partir da minha participação no projeto interdisciplinar EJA, me identifiquei, tanto é que não descarto lecionar para o ensino regular, mas a minha intenção é me qualificar cada vez mais para trabalhar com esse público alvo" (E01).

O terceiro tema "percebendo-se preparados para o estágio e para a experiência com a sala de aula com alunos deficientes", também reflete as especificidades dos subprojetos. Segue outro trecho da fala de um dos entrevistados: 
- Revista de Iniciação à Docência, v. 2, n. 2, 2017 Publicação: março, 2018 - ISSN 2525-4332

“...o Pibid por exemplo ajudou muito no meu estágio, quando eu fui para o estágio já não foi mais aquela coisa nova, aquele medo, eu já fui mais confiante e se tivesse um aluno deficiente na sala isso também me deixava mais segura devido ao projeto, coisa que se eu dependesse só da universidade eu não ia me sentir tão segura. Não só me preparou para eu me sentir mais segura na sala de aula como também quando eu tiver lidando com um aluno deficiente eu saber como lidar com aquele aluno"

(E08).

As falas evidenciam como a afinidade com o subprojeto contribuiu para os participantes se motivarem ainda mais em atuar no PIBID. Nesse sentido, o aluno E05 revela: "achei interessante a questão de trabalhar com essas pessoas com deficiência no meu subprojeto"; e E01 também declara que a partir de sua participação no Projeto Interdisciplinar EJA se identificou tanto que ele já não descarta lecionar no ensino regular.

Todos os entrevistados ressaltaram a importância do seu subprojeto por ter sido algo individual e direcionado conforme o segmento de cada área. Os entrevistados ressaltaram que através da especificidade destes foi possível se identificar e se apropriar mais da singularidade do subprojeto ao qual o aluno estava vinculado.

“...meu subprojeto foi Educação Ambiental em Itaibó/BA, no distrito, então assim, quando eu pude perceber aquele contexto, o interesse dos alunos é completamente diferente do que a gente conhece aqui da cidade; os alunos se interessam mais; eles buscam mais, eles indagam mais...eu me surpreendi, eu fiquei apaixonada pela educação do campo, eu quero trabalhar na educação do campo..." (E07).

Para Ciampa (2012) diferença e igualdade é uma primeira noção de identidade, mas a partir dos grupos sociais que participamos vamos nos diferenciando. Para o aluno E07 o contexto do subprojeto de que ela participou (Educação no Campo) deixou marcas em sua formação que só foram capazes de acontecer devido a especificidade dessa área por ela escolhida (subprojeto educação no campo). Ao fim de sua participação Eo7 considerou-se "apaixonada pela educação do campo", tanto que ela menciona que deseja trabalhar com a educação do campo.

Corroborando com o que Ciampa (2012) diz, os entrevistados se viram mudando a partir do contexto ao qual foram submetidos, e por mais que eles já tivessem sua identidade em formação, foram surpreendidos e perceberam que aquele contexto estava influenciando no seu processo de construção, sendo capazes de moldar a sua identidade. Logo, podemos concluir que a maneira como o projeto é desenvolvido, por meio de subprojetos específicos divididos por cada área de conhecimento, foi de uma contribuição significativa para as experiências de nossos entrevistados.

\section{Considerações Finais}

Através das análises dos resultados extraídos das falas dos entrevistados, encontramos vários indícios que marcam potenciais contribuições do PIBID para a formação dos alunos participantes. Neste sentido, buscamos atender ao objetivo principal da pesquisa, que foi 
- Revista de Iniciação à Docência, v. 2, n. 2, 2017 -

Publicação: março, 2018 - ISSN 2525-4332

investigar como o PIBID influenciou a formação identitária dos alunos de licenciatura em Ciências Biológicas da UESB.

Um dos pontos principais a ser destacado é o fato de que as falas dos alunos participantes da pesquisa evidenciam o PIBID como grande responsável por despertar uma maior identificação com a docência.

Vale destacar também os aspectos mais relevantes citados nas respostas dos entrevistados para cada categoria, como a importância da articulação entre teoria na realização das atividades proporcionadas pelo PIBID; o processo de mudança que eles perceberam em si mesmos, fundamental para a construção de suas identidades e as especificidades de cada subprojeto, permitindo experiências inteiramente particulares, sendo importantes para ajudar a compreender quais influências foram relevantes para despertar ou não o interesse em ingressar na carreira docente. Com a análise dos depoimentos obtidos concluímos que boa parte dos alunos participantes da pesquisa, de alguma forma, se consideraram mais atraídos pela educação. Talvez essa seja uma das virtudes do PIBID. Ademais, consideramos que o desenvolvimento de pesquisas no âmbito da formação de professores voltadas às discussões sobre políticas públicas de incentivo à docência seja capaz de proporcionar indicativos que podem contribuir com os cursos de licenciatura. Como vimos no decorrer das discussões do nosso trabalho os objetivos do PIBID, bem como as ações desenvolvidas por ele, têm um potencial significativo para colaborar para que haja dentro destes cursos uma formação docente mais sólida.

\section{Referências}

ALBINO, M. S.; MAGANHA, J. G. As contribuições do PIBID ao processo de formação inicial de professores. Polyphonía, v. 25/1, jan./ jun. 2014.

BARDIN, L. Análise de Conteúdo. Lisboa, Portugal: Edições 70, 1977.

BRASIL. Pibid - Programa Institucional de Bolsa de Iniciação à Docência. Professores da escola Básica In: Coordenação de Aperfeiçoamento de Pessoal de Nível Superior, 2014. Disponível em: <http://www.capes.gov.br/educacao-basica/capespibid/professores-de-escolas-pubicas >. Acesso em 22 ago. 2017.

CARMINATI, C. J. Professores de Filosofia: crise e perspectivas. Itajaí/SC: Universidade do Vale do Itajaí, 2006.

CIAMPA, A. C. Identidade. In: LANE, S. T. M.; CODO, W (Org.). Psicologia Social: o homem em movimento. 14 ed. Editora Brasiliense: São Paulo, 2012. p.58-75.

- Identidade humana como metamorfose: a questão da família e do trabalho e a crise de sentido no mundo moderno. Interações, v. 3, n. 6, 1998, p. 88.

FELÍCIO, H. M. S. O PIBID como "terceiro espaço" de formação inicial de professores. Rev. Diálogo Educ., Curitiba, v. 14, n. 42, p. 415-434, maio/ago. 2014. 
- Revista de Iniciação à Docência, v. 2, n. 2, 2017 -

Publicação: março, 2018 - ISSN 2525-4332

FLECK. S. C.; STHAL R. L. O estágio nos cursos de licenciatura: reflexões sobre as práticas docentes. Disponível

em: http://www.ucs.br/etc/conferencias/index.php/anpedsul/ganpedsul/paper/viewFile/1351/46. Avessado em 22 de agosto de 2017.

GAMA, A. G. B. et al. A Importância do Projeto PIBID na Formação dos Alunos de Licenciatura em Química do IFRN. Campus - Apodi. In: CONGRESSO DE INICIAÇÃO CIENTÍFICA DO IFRN, 9., 2013, Natal. Anais... Natal: IFRN, 2013.p. 1519-1525.

GIL, A. C. Como elaborar projetos de pesquisa. São Paulo: Atlas, 2002.

GONÇALVES, C. L.; MORAIS, M. A. F. O Pibid na formação inicial de professores: incentivo à profissão docente na perspectiva da pedagogia da autonomia. Disponível em: http://coloquio.paulofreire.org.br/participacao/index.php/coloquio/viii-

coloquio/paper/viewFile/191/269. Acesso em 20 de agosto de 2017.

MINAYO, M. C. S. (Org.) 1994. Pesquisa social: teoria, método e criatividade. Rio de Janeiro: Vozes, 2002.

MENDONÇA, L. B.; SOARES, M. N. As influências do PIBID na formação identitária dos licenciandos de Ciências Biológicas da UESB. In: Encontro Regional de Ensino de Biologia do Nordeste, 6., 2015, Vitória da Conquista. Anais...Vitória da Conquista/BA: SBENBIO, 2015. Disponível em: https://callforpapers.galoa.com.br/br/system/files/realm/vierebione/submissions/submission-35061293545-field_submission_fulltext_file2.pdf Acesso em: 22 de set.2017

PEREIRA, J. E. D. O ovo ou a galinha: a crise da profissão docente e a aparente falta de perspectiva para a educação brasileira. Revista Brasileira de Estudos Pedagógicos, v. 92, n. 230, p. 34-51, jan./abr. 2011.

RAMOS, N. V.; WIEBUSCH, A. As repercussões do Pibid na formação inicial de professores. Disponível em: http://www.ucs.br/etc/conferencias/index.php/anpedsul/ganpedsul/paper/viewFile/1584/463.

SANTOS, C, F; STHAL. L. R. O estágio nos cursos de licenciatura: reflexões sobre as práticas docentes. In: ASSOCIAÇÃO NACIONAL DE PÓS-GRADUAÇÃO E PESQUISA EM EDUCAÇÃO-SUL, 9., 2012, Caxias do Sul. Anais...Rio Grande do Sul: UCS, 2012. Disponível em: http://www.ucs.br/etc/conferencias/index.php/anpedsul/ganpedsul/paper/view/1351/462. Acesso em 22 set.2017

SIQUEIRA. M.; MASSENA. E. P.; BRITO L. D. Contribuições do Pibid à construção da identidade e saberes docente de futuros professores de ciências. In: Encontro Nacional de Pesquisa em Educação em Ciências, 9., 2013, Águas de Lindóia. Anais...Águas de Lindóia/SP: ABRAPEC, 2013. Disponível em: http://www.nutes.ufrj.br/abrapec/ixenpec/atas/resumos/R1037-1.pdf. Acesso em: 05 do 07 de 2017

UESB. Projeto Institucional de Bolsas de Iniciação à Docência - PIBID: Microrrede: Ensinoaprendizagem-formação. Jequié: UESB, 2013. Disponível em: http://pibid.uesb.br/ava/login/index.php. Acesso em: 22 de agosto de 2017.

VICENTE, M. F. Formação inicial de professores: relação teoria e prática no Pibid. Rev. Didática e Prática de Ensino na relação com a Formação de Professores. EdUECE- Livro, 2014.

ZEICHNER, K. Repensando as conexões entre a formação na universidade e as experiências de campo na formação de professores em faculdades e universidade. Educação, v. 35, n. 3, p. 479-504, maio/ago. 2010. 
- Revista de Iniciação à Docência, v. 2, n. 2, 2017 -

Publicação: março, 2018 - ISSN 2525-4332

WIEBUSCH. A.; RAMOS. V. N. As repercussões do PIBID na formação inicial de professores. In: ASSOCIAÇÃO NACIONAL DE PÓS-GRADUAÇÃO E PESQUISA EM EDUCAÇÃO-SUL, 9., 2012, Caxias do Sul. Anais... Rio Grande do Sul: UCS, 2012. Disponível em: http://www.ucs.br/etc/conferencias/index.php/anpedsul/ganpedsul/paper/viewFile/1584/463. Acesso em 22 set.2017. 